\author{
البصيرة: مبلة الصراهات الإهلامية \\ AL-BASHIRAH: JOURNAL OF ISLAMIC STUIDES \\ Vol. 1 No. 1(2020): 200-217
}

Website: https://journal.stiba.ac.id

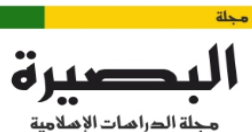

AL-BASHIRAH

\title{
منهج فقهاء الثافعية في عرض الفروق الفقهية
}

\author{
أحمد حنفي داعين يونتا

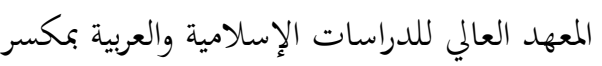

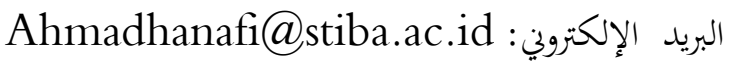

\begin{abstract}
المستخلص
سلك بعض فقهاء الشافعية في عرض المسائل الفقهية عن طريق ذكر الفرق بين المسائل المتفقة صورة المختلفة حكما وهو الشهير بالفروق

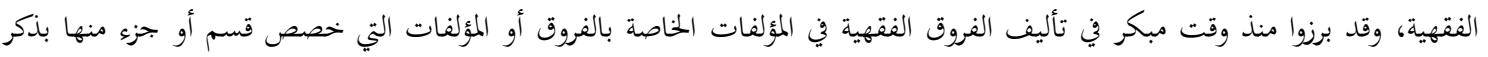

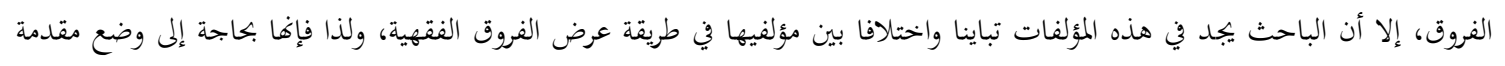

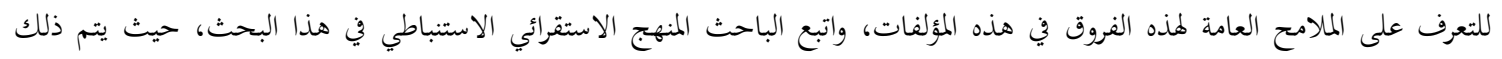

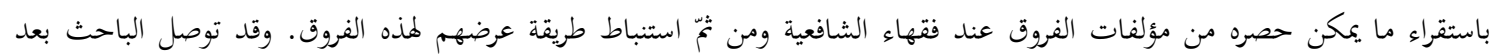

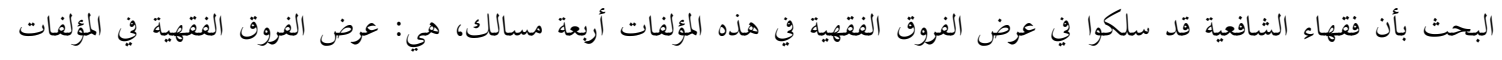

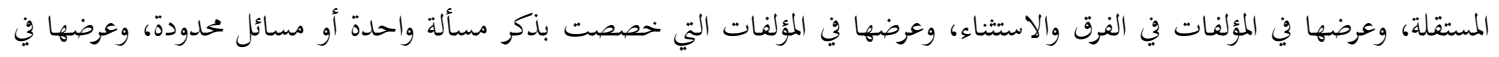
المؤلفات التي تناولت فيها الفروق الفقهية تبعا. الكلمات المفتاحية: فقهاء الشافعية, الفروق الفقهية، الفقه, منهج, المؤلفات.
\end{abstract}

\section{Methodology in Presenting of al-Furūq al-Fiqhiyyah by Fukahā in Shafi'i School}

\author{
Akhmad Hanafi Dain Yunta \\ Sekolah Tinggi Ilmu Islam dan Bahasa Arab (STIBA) Makassar, Indonesia \\ Email: Ahmadhanafi@stiba.ac.id
}

\begin{abstract}
Several scholars of fiqh of the Shafi'i School in presenting fiqh issues used the method of deciphering aspects of the differences between legal issues that had a similar picture but had differences in terms of the law, which was later known as al-furuq al-fighiyyah. Since the beginning of the writing of al-furuq alfiqhiyyah, there had been some literature that discussed it specifically or which specializes it in a subdiscussion. However, the researcher found in this literature that there are significant differences in the method of presentation among the authors. Because of that, it is considered important to formulate a separate method of approach as a general standard to recognize the character of scientific works on alfuruq al-fiqhiyyah. In this study, the researcher used the inductive istinbat method of approach, by inducing possible and representative works of literature related to al-furuq al-fighiyyah in the Shafi'i School. This study found that the Fuqaha of Shafi'i school used four ways in presenting the discussion of
\end{abstract}

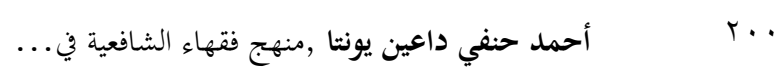




\section{البصيرة: مجلة الدراهات الإهلامية AL-BASHIRAH: JOURNAL OF ISLAMIC STUIDES \\ Vol. 1 No. 1(2020): 200-217}

Website: https://journal.stiba.ac.id

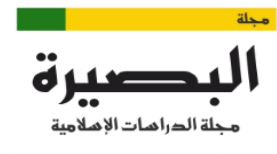

AL-BASHIRAH

al-furuq al-fiqhiyyah, namely: Describing the discussion of al-furuq al-fiqhiyyah in one separate literature, describing it in the literature related to al-farq (differences), and al-istisna' (exception), describing it in the literature that specifically discusses a particular problem or issues, and describes it in the literature that simply inserted a discussion of al-furuq al-fiqhiyyah as a complement.

Keywords: Scholars of fiqh of the Shafi'i School, al-furüq al-fiqhiyyah, fiqh, method, literature.

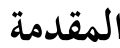

إن الحمد لله نحمده ونستعينه ونستغفره، ونعوذ بالله من شرور أنفسنا وسيئات أعمالنا، من يهله

الله فلا مضل له، ومن يضلل فلا هادي له، وأشهد أن لا إله إلا الله وحده لا شريك له وأشهد أن محمدا عبده ورسوله، صلى الله عليه وعلى آله وصحبه وسلم تسليما كثيرا. أما بعد:

فإن علم الفقه من أجلّ العلوم الشرعية وأهمها، والاشتغال به دراسة، وتدريسا، وبحثا من أفضل

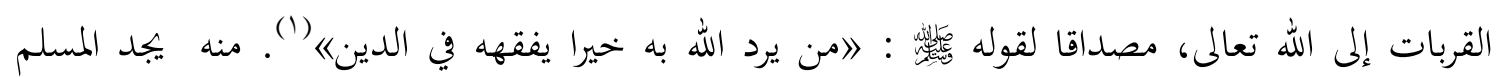
بصيرته للامتثال، وبه ينجو من طريق المغضوب عليهم الذين يعلمون بلا عمل، وطريق الضالين الذين يعملون بلا علم.

من أجل ذلك فقد تنوعت مسالك العلماء في تحلية هذا العلم وبيانه للناس، ومن أدق هذه المسالك بيان الفروق وأوجه الخلاف بين المسائل الفقهية المتشاهة التي قد تشتبه على بعض الناس فيظنون أن حكمها واحد لا يختلف. لأجله ألف الفقهاء كتبا في هذا الفن واشتهرت هذه الصنعة الفقهية باسم الفروق الفقهية. وكتب الفروق هذه تزيل كثيرا من الشبه الواردة، وتكسب الدقة في النظر للأحكام عند التمييز بينها ـ قال الإسنوي -رحمه الله- : اإن المطارحة بالمسائل ذوات المآخذ المؤتلفة المتفقة، والأجوبة المختلفة المفترقة محا يثير أفكار الحاضرين في المسالك، ويبعثها على اقتناص أبكار المدارك، ويميز مواقع أقدار

(') أخرجه البخاري في العلم باب من يرد الله به خيرا يفقهه في الدين رقم (VI)، ومسلم في الزكاة باب النهي عن

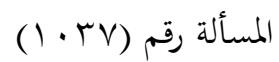

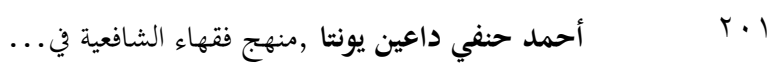




\section{البصيرة: مجلة الدراهات الإهلامية AL-BASHIRAH: JOURNAL OF ISLAMIC STUIDES \\ Vol. 1 No. 1(2020): 200-217}

Website: https://journal.stiba.ac.id

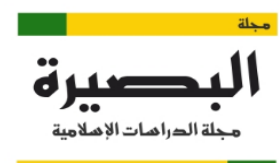

AL-BASHIRAH

الفضلاء، ومواضع بحال العلماء《)" )، وقال السيوطي -رحمه الله- : 》ابه يطلع الفقيه على حقائق الفقه ومداركه وأسراره ومآخذه وتمهر في فهمه واستحضاره《) (r). وقد تميز بعض فقهاء الشافعية في عرض المسائل الفقهية عن طريق ذكر الفرق بين المسائل المتفقة صورة المختلفة حكما، وقد برزوا منذ وقت مبكر في تأليف الفروق الفقهية في المؤلفات الخاصة بالفروق أو المؤلفات التي خصص قسم أو جزء منها بذكر الفروق، إلا أن الباحث يجد في هذه المؤلفات تباينا واختلافا بين مؤلفيها في طريقة عرض الفروق الفقهية، ولذا فإنا بحاجة إلى البحث في وضع مقدمة للتعرف على الملامح العامة لمذه الفروق في هذه المؤلفات متبعا فيه المنهج الاستقرائي الاستنباطي، حيث يتم ذلك باستقراء ما يمكن حصره من مؤلفات الفروق عند فقهاء الشافعية ومن ثيّ استنباط طريقة عرضهم لهذه الفروق.

أسئلة البحث :

يهرف هذا البحث للإجابة على هذين السؤالين؟

ا ـ ما هي الفروق الفقهية عند فقهاء الشافعية؟

r. ما هو منهج فقهاء الشافعية في عرض الفروق الفقهية في مؤلفاقم الخاصة لمذه الفروق؟

تعريف علم الفروق الفقهية عند الثافعية

لم يذكر فقهاء الشافعية -على حسب اطلاع الباحث- تعريفا مستقلا لهذا العلم، إلا أن بعضهم ذكر وصفا عاما دالا على ماهية هذا العلم، من ذلك:

1 ما ذكره السيوطي -رحمه الله-: اهو الفن المسمى بالفروق، الذي يذكر فيه الفرق بين النظائر

المتحدة تصويرا ومعنى، المختلفة حكما وعلة) (ع).

ץ ما ذكره الفاداني -رحمه الله-: الوهو الفن المسمى بالفروق، أي الذي يفرق فيه بين النظائر

$$
\begin{aligned}
& \text { (') ينظر : مطالع الدقائق في تحرير الجوامع والفوارق ص : } 1 .
\end{aligned}
$$

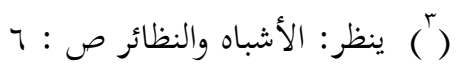

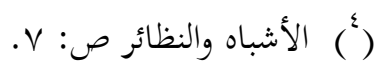

$$
\begin{aligned}
& \text { أحمد حنفي داعين يونتا , منهج فقهاء الشافعية في... T. T }
\end{aligned}
$$




\section{البصيرة: مجلة الدراهات الإهلاهية AL-BASHIRAH: JOURNAL OF ISLAMIC STUIDES \\ Vol. 1 No. 1(2020): 200-217}

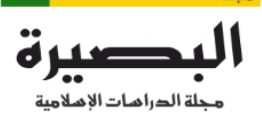

AL-BASHIRAH

Website: https://journal.stiba.ac.id

\section{المتحدة صورة، المختلفة حكما وعلة《) (ن.}

يلاحظ أن ما ذكر من هذين النصين عبارة عن وصف عام للفروق الفقهية وليس تعريفا لهذا العلم، إلا أغما قد اتفقا بأن الفروق هي: المسائل المتشاهة في الصورة، والمختلفة في الحكمي والعلة (7).

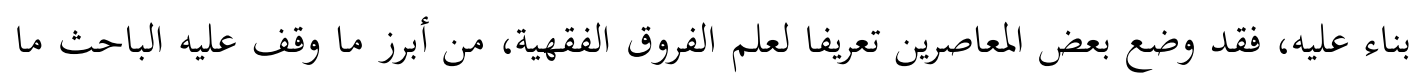
يلي: 1 ما ذكره الدكتور عمر السبيل: الالعلم ببيان الفرق بين مسألثين فقهيتين متشاهتين صورة،

$$
\text { مختلفتين حكما《 (v) }
$$

r ما ذكره الدكتور يعقوب الباحسين: العلم الذي يبحث فيه عن وجوه الاختلاف وأسباهما بين

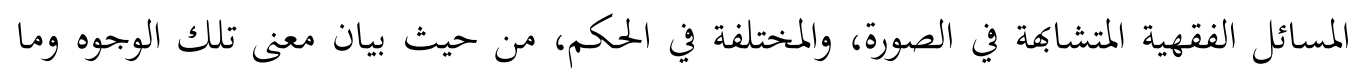
له صلة بها، ومن حيث صحتها وفسادها، وبيان شروطها ووجوه دفعها، نشأتها وتطورها، وتطبيقاتها، والثمرات المترتبة عليهاه (^). r ما ذكره الدكتور عبد الرمن بن عبد الله الشعلان: لاإبراز التمايز بين أمرين فقهيين متشاهين

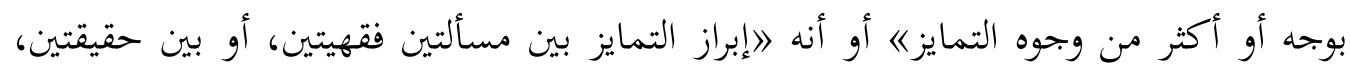

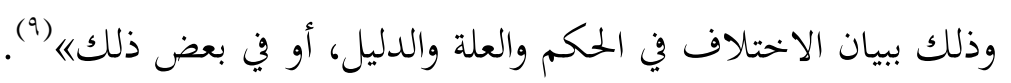

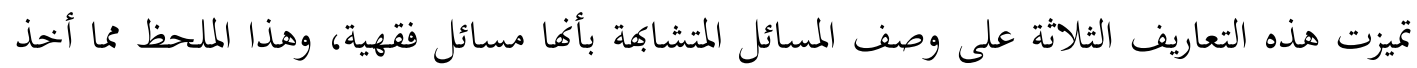

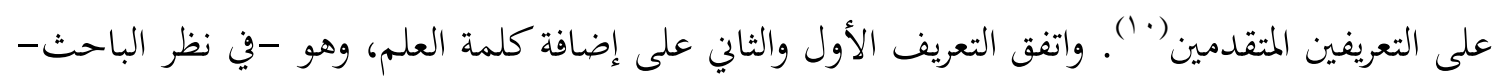

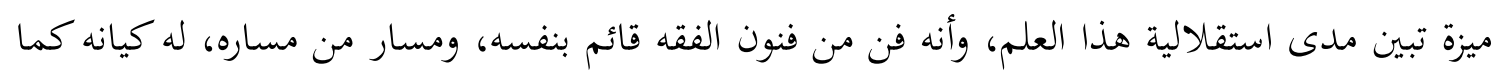

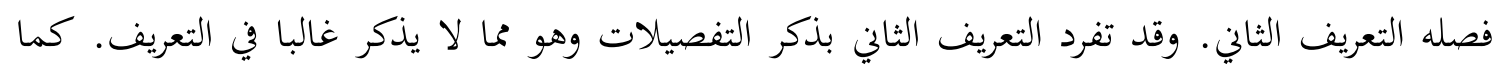

$$
\begin{aligned}
& \text { ( ) ( ) الفوائد الجنية حاشية المواهب السنية للفاداني /9/ }
\end{aligned}
$$

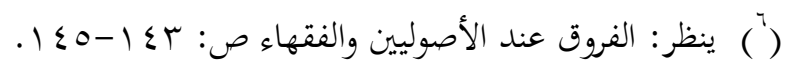

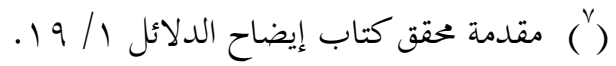

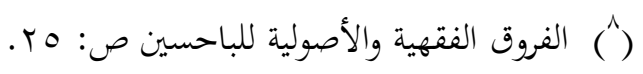

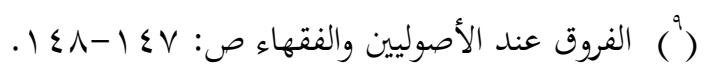

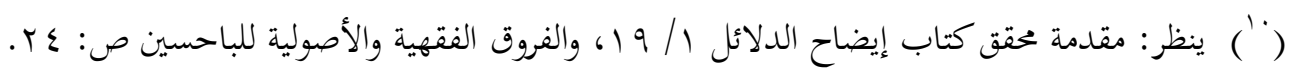

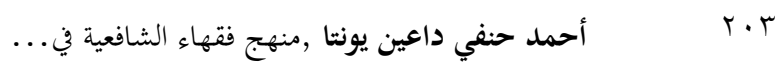




\section{البصيرة: مجلة الدراهات الإهلاهية AL-BASHIRAH: JOURNAL OF ISLAMIC STUIDE்S \\ Vol. 1 No. 1(2020): 200-217}

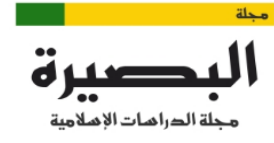

AL-BASHIRAH

Website: https://journal.stiba.ac.id

تفرد التعريف الثالث بحيث لم يذكر كلمة (العلم) التي أثتبه التعريف الأول والثاني، والاكتفاء بقوله (إظهار

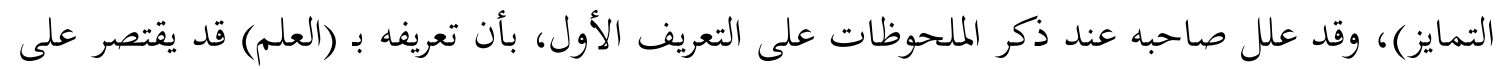

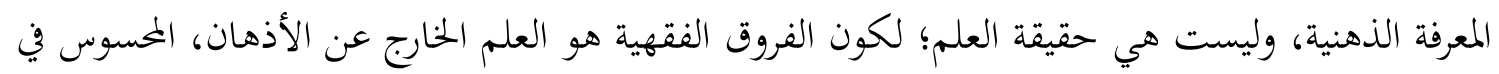

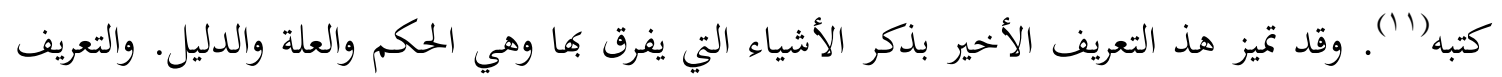
المختار عند الباحث هو: (العلم الذي يبحث فيه عن وجوه الاختلاف وأسباهما بين المسائل الفقهية

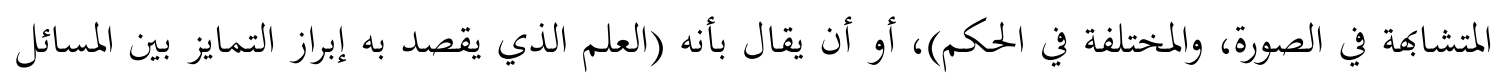

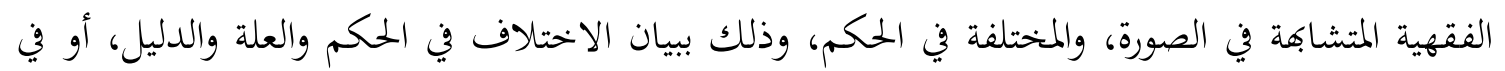
بعض ذلك)، والله تعالى أعلم.

\section{موضوع علم الفروق الفقهية وفوائده.}

موضوع هذا العلم: فإن هذا العلم يبحث عن المسائل الفقهية المتشاهة في صورتا، المختلفة

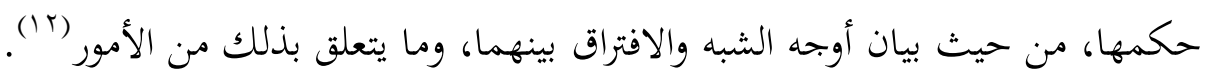
وأما فوائده، فتتجلى في أمور (r) آ) منها: ا بيان بأنه لا تناقض في الشريعة، وأها فرقت بين تلك المسائل المتشاهة في الصورة؛ لافتراقها في

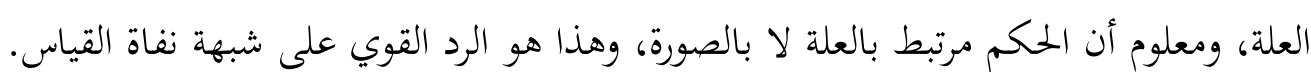
r بيان منزلة العلماء وعظيم قدرهم، حيث فرقوا بدقيق نظرهم هذه المسائل التي يتوهم الناظر فيها أغها متماثلة.

r + إبراز أسباب الفروق بين المسائل التي فرق العلماء باجتهادهم، فيه بيان أن تلك الفروق مبنية على أساس علمي، وليس على هوى النفس.

ع -تبصير العالم بحقائق الأحكام، وإنارة الطريق أمامه مما يصونه من التعثر في الاجتهاد، ومنعه من

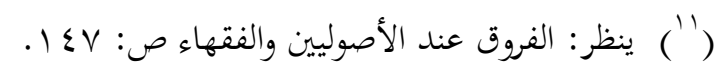
(")

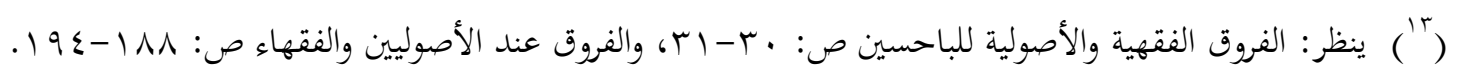

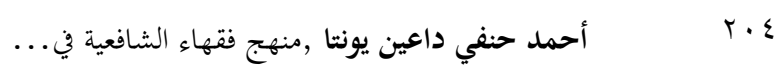




\section{البصيرة: مجلة الدراهات الإهلاهية AL-BASHIRAH: JOURNAL OF ISLAMIC STUIDÉS \\ Vol. 1 No. 1(2020): 200-217}

Website: https://journal.stiba.ac.id

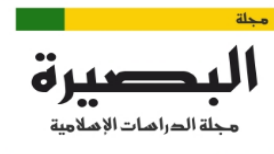

AL-BASHIRAH

الوقوع في الوهم أو الاستعجال عند الحكم على المسائل المتشاجة بالنظر المجرد إلى الشبه

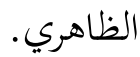

ه بإعانة الفقيه على القياس الصحيح بين المسائل، ويتحقق له غلبة الظن واطمئنان القلب في إلحاق

$$
\text { الفروع بالأصول. }
$$

7 ت تكرار القراءة في كتب الفروق ومسائلها التي تذكر علل الفرق، يولد لدي العالم ملكة يستطيع

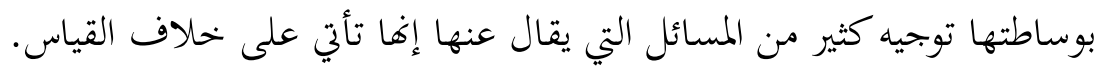

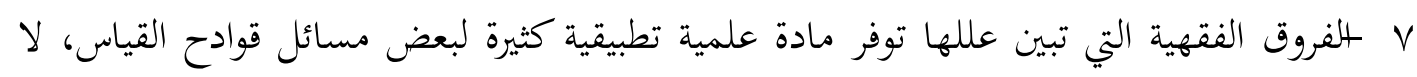

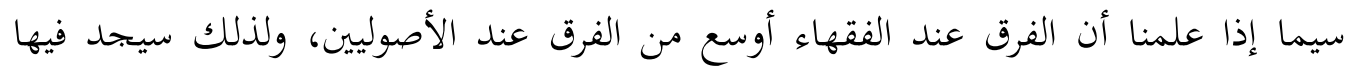
طالب العلم أمثلة لعدة قوادح، وهو موضوع تعوزه الأمثلة مع أنه لا يفهم إلا بما.

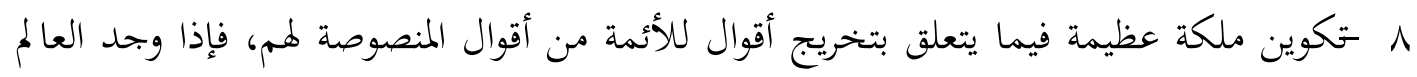

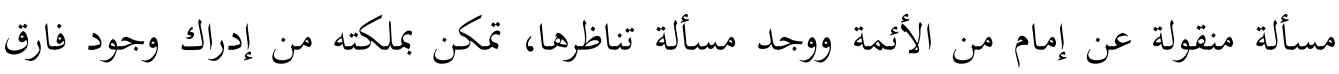

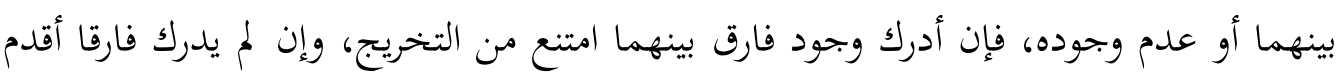
على التخريج. 9 لالفروق المستندة إلى نص الكتاب أو السنة ولم تظهر علة التفريق فيها يترتب عليها مقصد شرعي مهم، ألا وهو تحقيق الاستسلام لله تعالى والخضوع لأحكامه.

\section{منهج فقهاء الشافعية في عرض الفروق الفقهية في المؤلفات الخاصة بها}

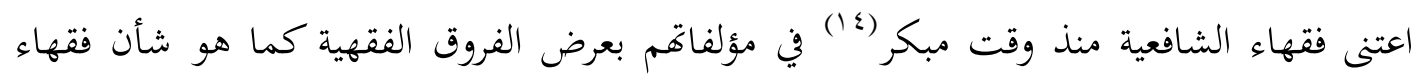

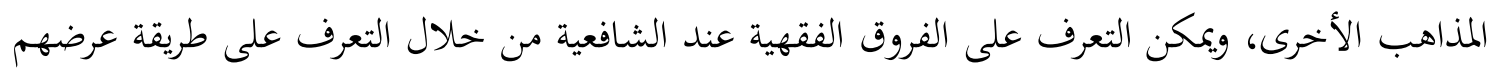

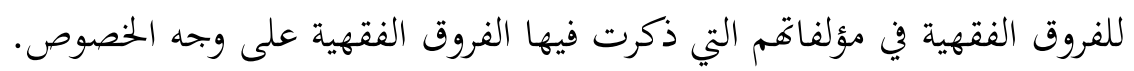

(") قال الدكتور يعقوب الباحسين: (إن الذي يبدو، من خلال النظر في المؤلفات في هذا العلم، أن القرن الرابع الهجري

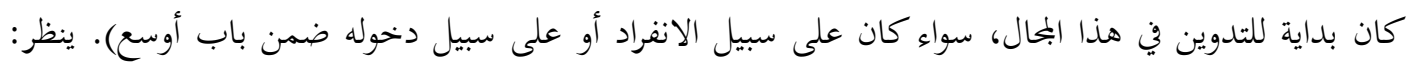

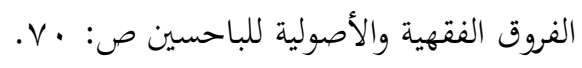

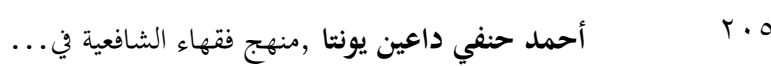




\section{البصيرة: مجلة الدراهات الإهلامية AL-BASHIRAH: JOURNAL OF ISLAMIC STUIDES \\ Vol. 1 No. 1(2020): 200-217}

Website: https://journal.stiba.ac.id

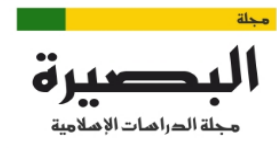

AL-BASHIRAH

سلك فقهاء الشافعية في عرض الفروق الفقهية في المؤلفات التي خصصت أو قسم منها بذكر الفروق مسالك عدة، ويككن حصر هذه المسالك إلى أربعة أقسام (10) الأول: المؤلفات في الفروق الفقهية استقلالا. الثاني: المؤلفات في الفرق والاستثناء. الثالث: المؤلفات في مسألة واحدة أو مسائل محدودة. الرابع: المؤلفات التي تناولت الفروق الفقهية تبعا.

القسم الأول: المؤلفات في الفروق الفقهية استقلالا.

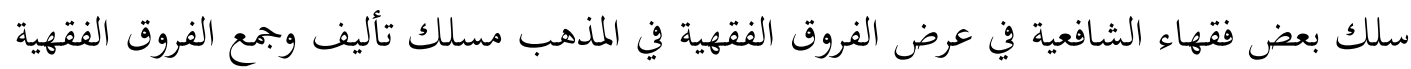

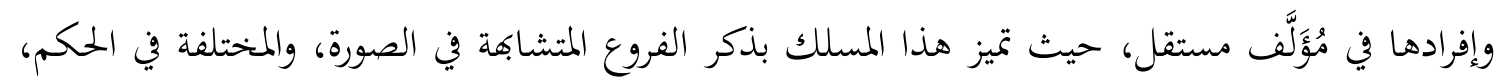

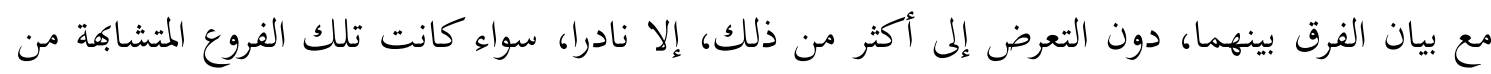

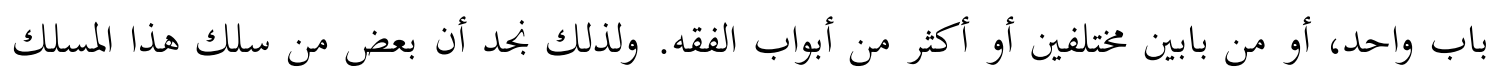
إطلاق مؤلفاقم باسم الفروق أو النظائر (17). ومن مؤلفات الفروق عند الشافعية في هذا المسلك:

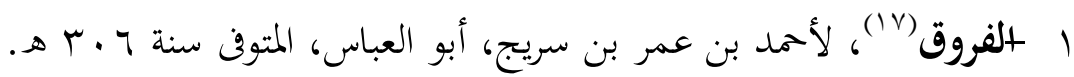

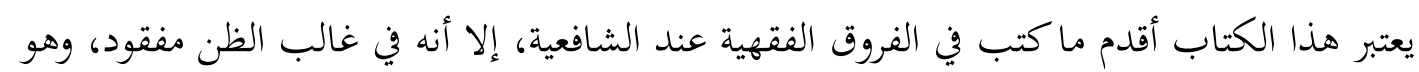
مشتمل على أجوبة متعلقة بمختصر المزين (1).

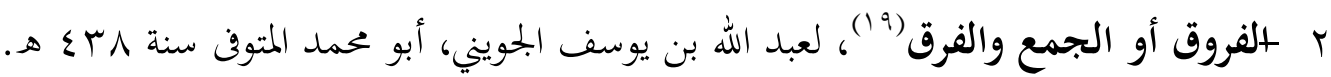
(") استفاد الباحث هذا التقسيم من تقسيم الدكتور يعقوب الباحسين في كتابه الفروق الفقهية والأصولية، عند بكثه

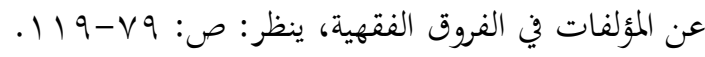

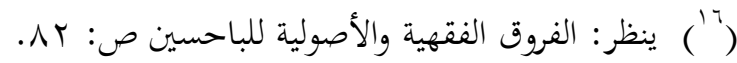

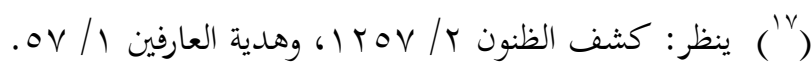

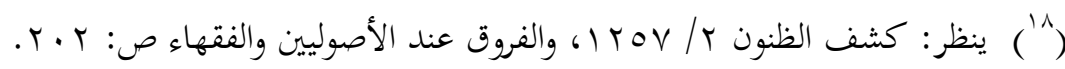

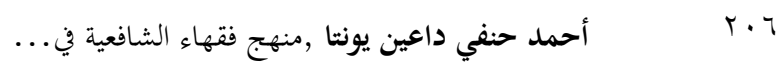

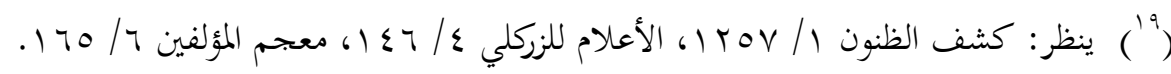




\section{البصيرة: مجلة الدراهات الإهلامية AL-BASHIRAH: JOURNAL OF ISLAMIC STUIDES \\ Vol. 1 No. 1(2020): 200-217}

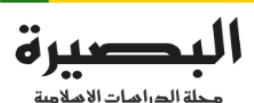

مجلة الدراهات الإهلامية

AL-BASHIRAT

Website: https://journal.stiba.ac.id

يُعدّ هذا الكتاب من أكبر ما ألف في الفروق عند الشافعية على وجه الاستقلال. وقد صدّره مؤلفه بمقدمة عن علم الفروق، وسبب تأليف الكتاب، قال -رحمه الله-: \افإن مسائل الشرع ربما تتشابه صورها، وتختلف أحكامها، لعلل أوجبت اختلاف الأحكام، ولا يستغني أهل التحقيق عن الاطلاع على تلك العلل التي أوجبت افتراق ما افترق منها، واجتماع ما اجتمع منها، فجمعنا في هذا الكتاب بمشيئة الله تعالى وحسن توفيقه مسائل وفروقا بعضها أغمض من بعض، وكنا رأينا لبعض مشايخنا المتقدمين مجموعا في هذا الباب، غير أنه كان مشتملا على مسائل معدودة قليلة، ولا يكاد يكصل مقصود هذا الباب إلا بالزيادة على ما جمع المتقدمون، غير أن لما وجدناه قدرة تبركنا، واقتدينا، وتأسينا، وبنينا على أساس من تعميم تشييد أساسه/) (r.)

والكتاب مرتب على أبواب الفقه، احتوى على فروع كثيرة ودقيقة، إذ جمع فيما يزيد على ( . . I ) فرق، بل أورد من الفروق ما لا يوجد في كتاب غيره(r(T). قال عنه الطويف -رحمه الله-: لاومنهم الجويني من أصحاب الشافعي، له كتاب الجمع والفرق، صدّره بيسير من الفروق الأصولية، وهو أكبر ما رأيت من

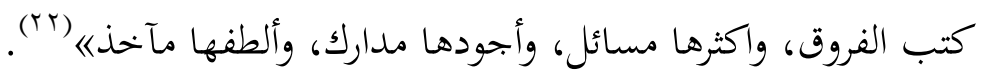
وقد قام الباحث عبد الرحم المزيني بتحقيق الكتاب وذلك في مرحلتي الماجستير في كلية الشريعة

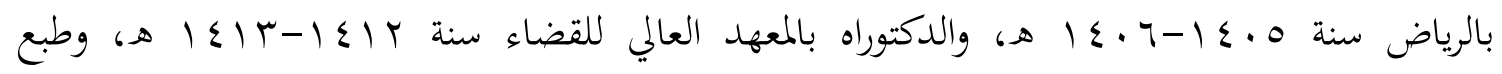
الكتاب وتم نشره عن طريق دار الجيل في بيروت، في ثلاث بحلدات تحت عنوان (الجمع والفرق)

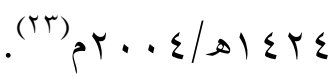

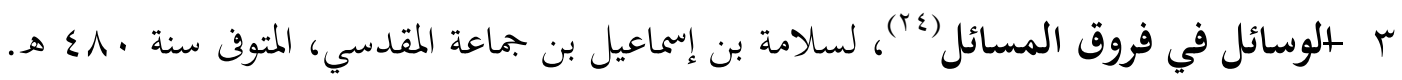

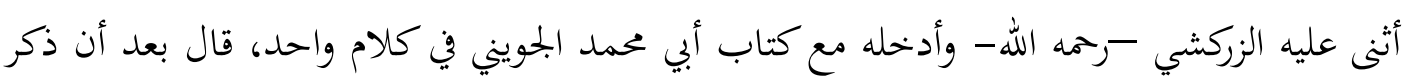

$$
\text { rV/ / الجمع والفرق (r) }
$$

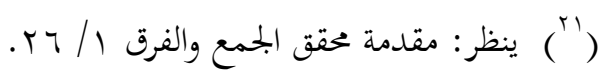

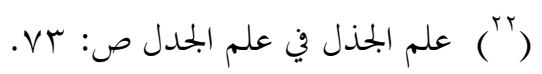

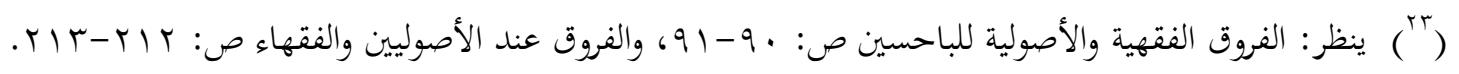

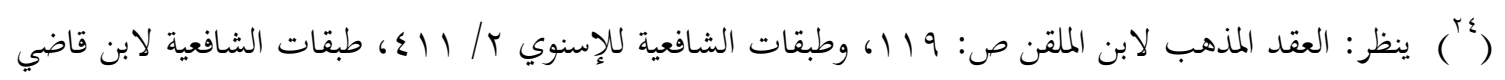

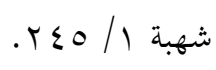




\section{البصيرة: مجلة الدراهات الإهلامية AL-BASHIRAH: JOURNAL OF ISLAMIC STUIDES \\ Vol. 1 No. 1(2020): 200-217}

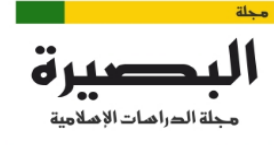

AL-BASHIRAH

Website: https://journal.stiba.ac.id

النوع الثاني من أنواع الفقه، وهو الجمع والفرق: الومن أحسن ما صُيّْف فيه كتاب الشيخ أبي محمد الجويني

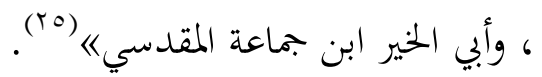

قال الدكتور الشعلان: اوالكتاب قيم، وقد يفرق بين المسألثين بفرق واحد، وقد يزيد، وهو مرتب المبر

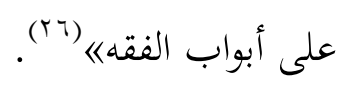

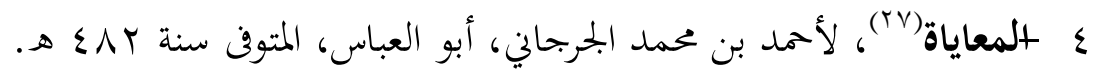

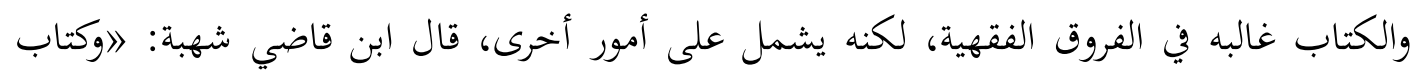

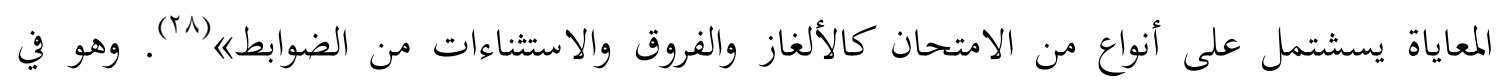

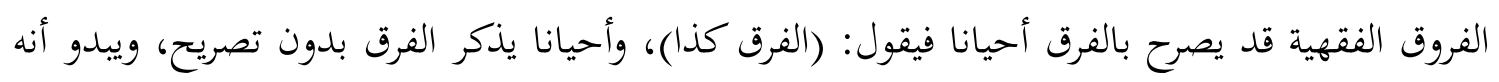

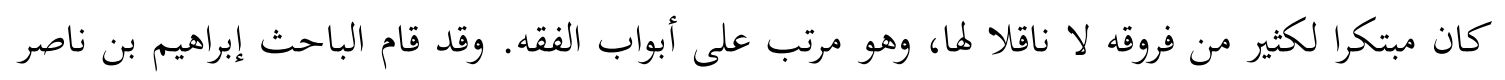

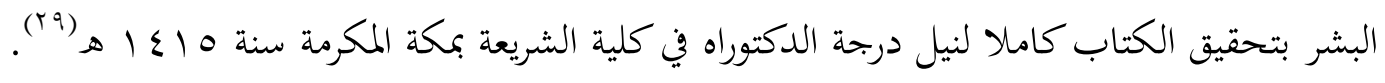

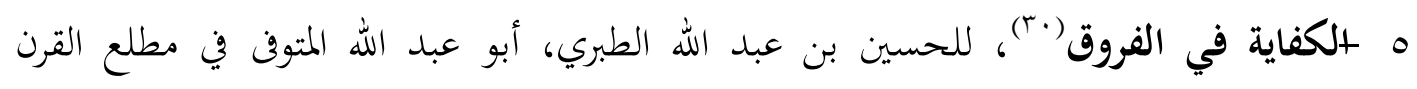

$$
\text { الخامس الهجري. }
$$

ذكر الإسنوي وغيره أن كتابه هذا يقارب المختصر المعروف بالتبريزي ووصفوه بأنه مختصر مليح، وأنه يعرف بـ (الكفاية في الفروق واللطائف) (").

$$
\begin{aligned}
& \text { (") }
\end{aligned}
$$

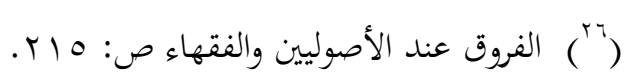

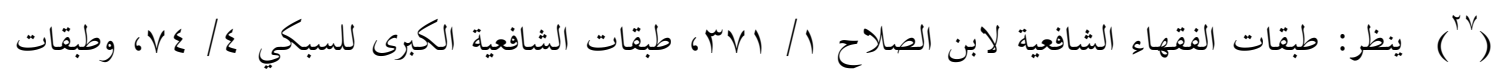

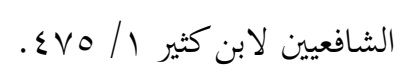

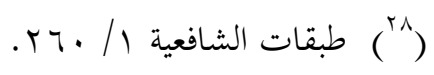

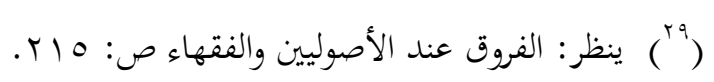

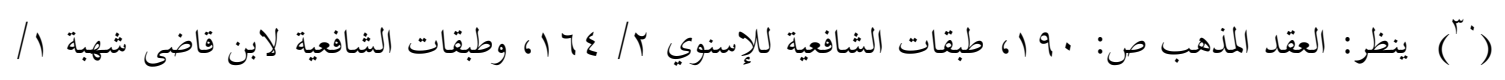

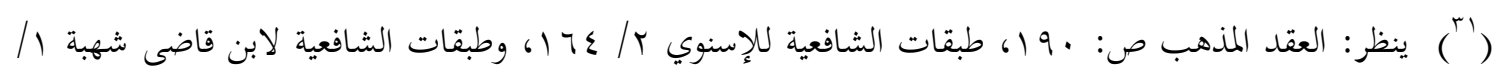




\section{البصيرة: مجلة الدراهات الإهلاهية AL-BASHIRAH: JOURNAL OF ISLAMIC STUIDE்S \\ Vol. 1 No. 1(2020): 200-217}

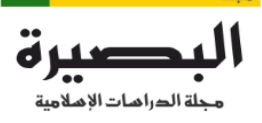

AL-BASHIRAH

Website: https://journal.stiba.ac.id

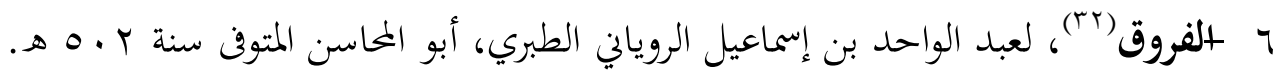

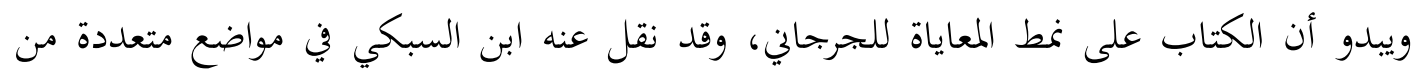

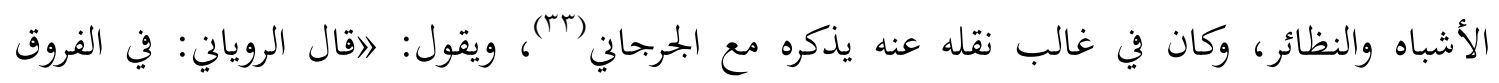

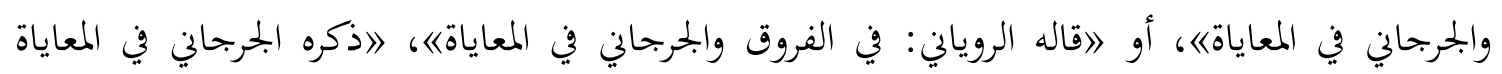

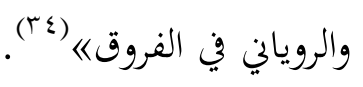

V t لفصول والفروق(ب0)، لنجم الدين أحمد بن محمد بن خلف بن راجح المقدسي، أبو العباس

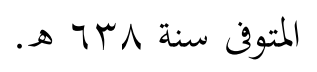

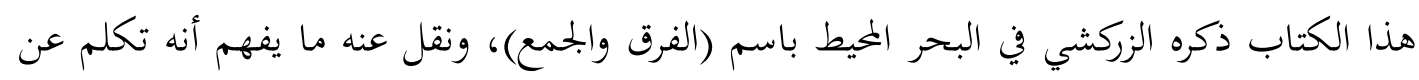

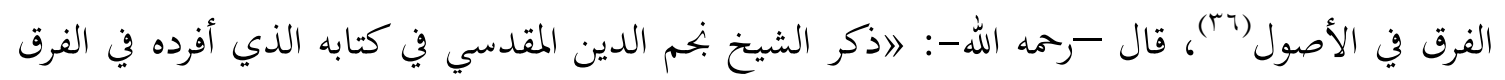

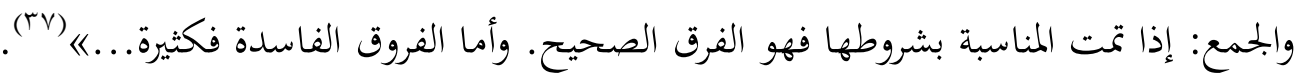

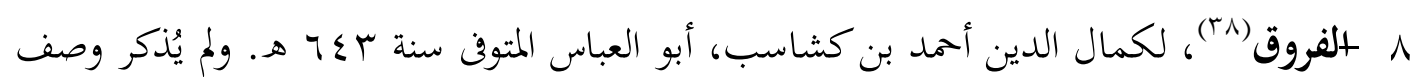

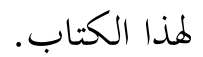
و +الجمع والفرق(19)، لسراج الدين يونس بن عبد البميد بن علي الهذلي الأرمنتي، المتوفى سنة

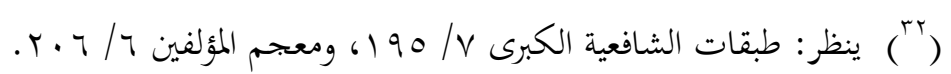
(")

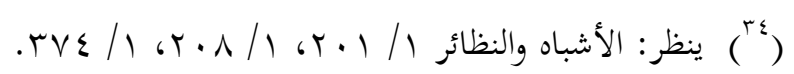

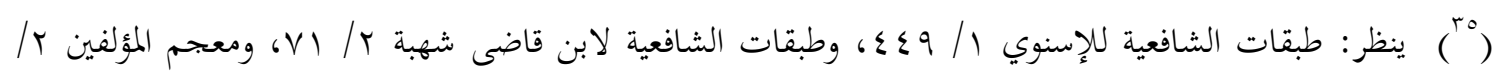
.99 ( 99 (T) (T)

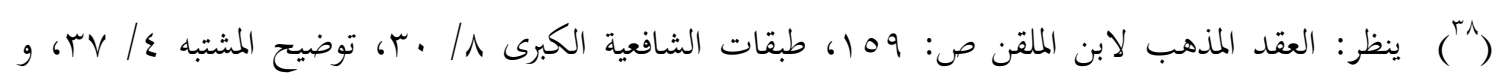

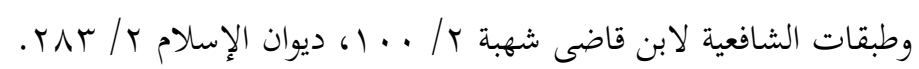

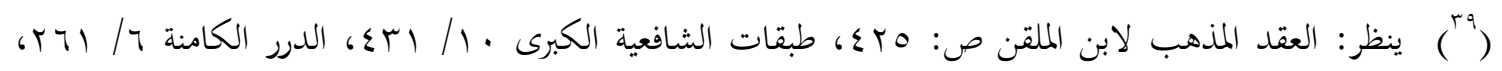

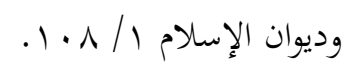

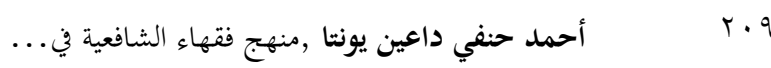




\section{البصيرة: مجلة الدراهات الإهلاهية AL-BASHIRAH: JOURNAL OF ISLAMIC STUIDES \\ Vol. 1 No. 1(2020): 200-217}

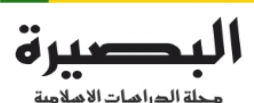

مجلة الصراهات الإهلامية

AL-BASHIRAH

Website: https://journal.stiba.ac.id

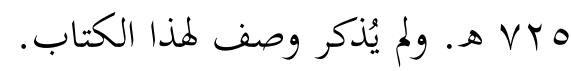

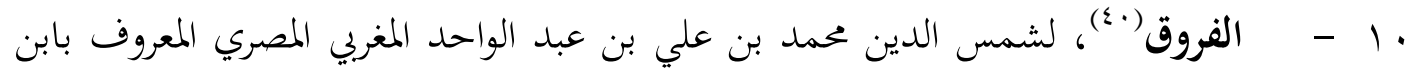

النقاش، أبو أمامة المتوفى سنة سجV هـ. وذكر بعضهم أن اسم الكتاب (النظائر والفروق).

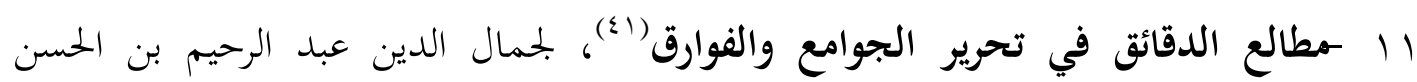

الإسنوي، المتوفن سنة VVY هـ.

الكتاب خاص بالفروق الفقهية، ورتبه على أبواب الفقه، وكان من منهجه أن يذكر فرعين متشاهين،

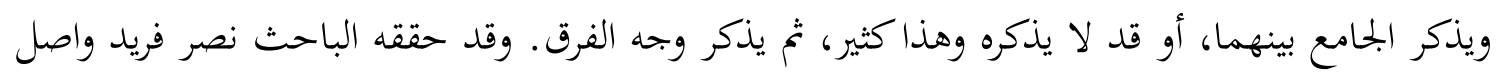

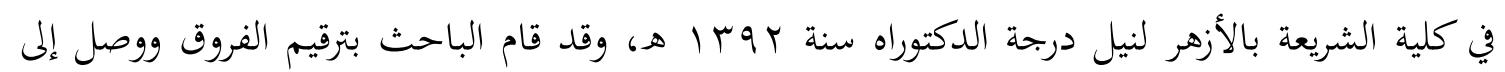

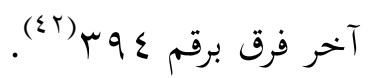

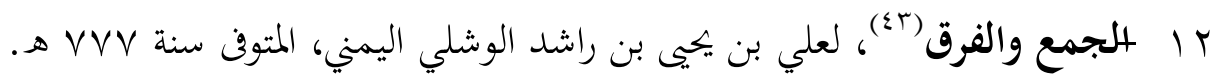

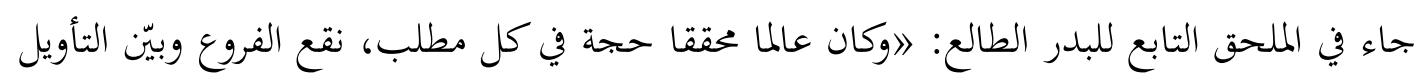

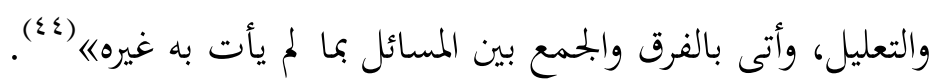

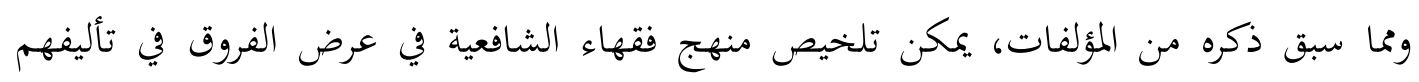
الفروق الفرعية في مؤلفات مستقلة، في الأمور التالية: ا ـ ذكر الفروق مرتبة على أبواب الفقه.

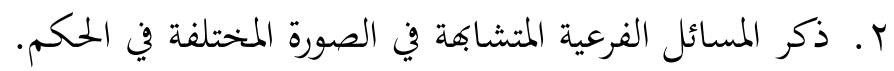
r. ب. ذكر الفروق مرتبة على أبواب الفقه. ع. ذكر وجه الفرق بين المسألتين، وقد يذكر بعضهم الجامع بينهما.

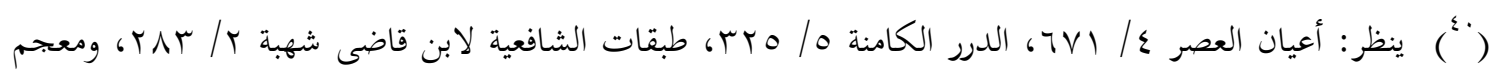

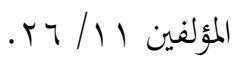

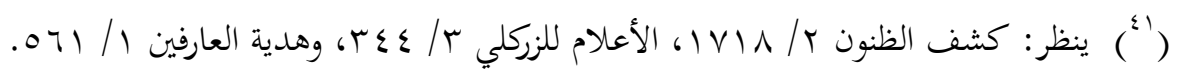

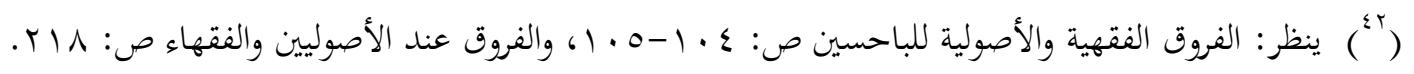

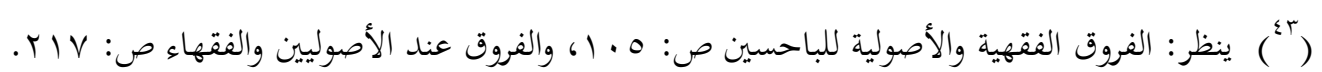

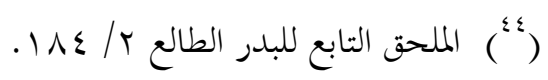

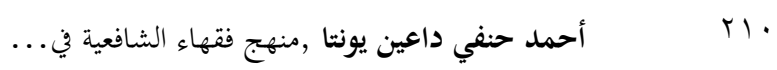




\section{البصيرة: مجلة الدراهات الإهلامية AL-BASHIRAH: JOURNAL OF ISLAMIC STUIDES \\ Vol. 1 No. 1(2020): 200-217}

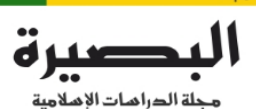

مجلة الصراهات الإهلامية

AL-BASHIRAH

Website: https://journal.stiba.ac.id

هـ تباين عدد الفروق في كل من هذه المؤلفات بين مُكثِر ومُمِقِّ.

7 ـ ـ تميز بعضهم بذكر الفروق الدقيقة والغامضة، وبعضهم بالفروق التي لم يذكروها غيرهم.

القسم الثاني: المؤلفات في الفرق والاستثناء.

سلك بعض فقهاء الشافعية وهم قلة، في عرض الفروق الفقهية بتأليف المؤلفات في الفرق والاستثاء. ويعني هذا المسلك أن المؤلف يذكر القاعدة أو الضابط أو الحكم الفقهي العام، ثم يذكر الجزئيات المستثناة من ذلك كما في عموم كتب القواعد الفقهية، بل في بعض كتب الفقه، ولكن المقصود هو الكتب المؤلفة أصالة في هذا الموضوع (0)؛

ومن مؤلفات فقهاء الشافعية التي اتخذ مؤلفوها هذا النهج:

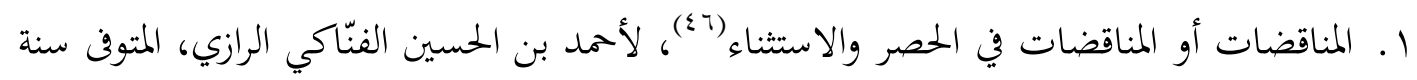

.$\infty \varepsilon \varepsilon \wedge$

قال ابن الصلاح-رحمه الله-: ارأيت له كتاب المناقضات، ومضمونه: الحصر والاستثناء، شبه

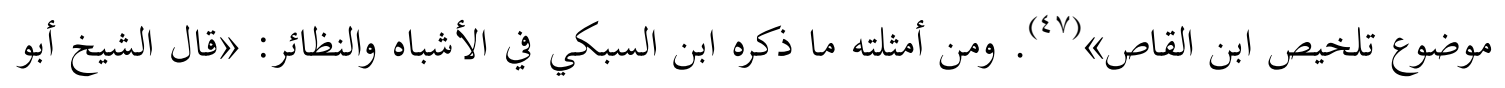
الحسين الفنّاكي من قدماء أصحابنا من تلامذة الشيخ أبي حامد في كتاب له يسمى المناقضات: من له اشترى شيئا شراء صحيحا لزمه الثمن؛ إلا في مسألة واحدة وهي المضطر يشتري الطعام بثمن معلوم فإنه لا يلزم الثمن؛ وإنما تلزم قيمته، ذكره أبو علي الطبري، واحتج له بأن النبي -صلى الله عليه وسلم- فهى الهى

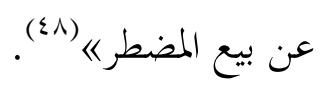

(")

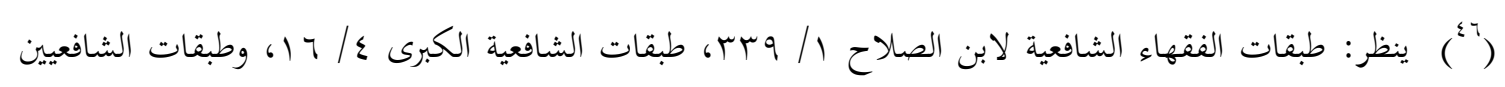

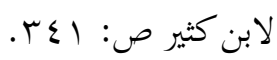

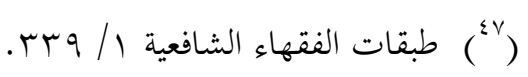

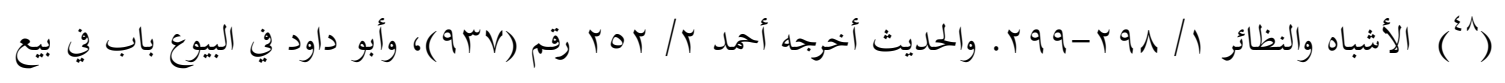

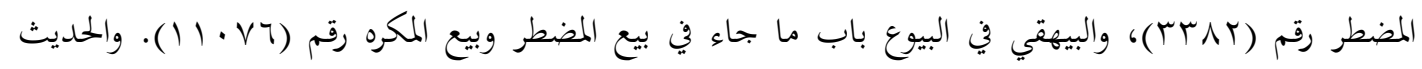

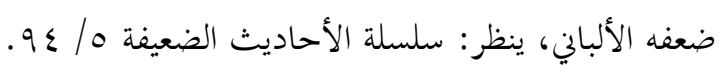

أحمد حنفي داعين يونتا ,منهج فقهاء الشافعية في... TII 


\section{البصيرة: مجلة الدراهات الإهلامية AL-BASHIRAH: JOURNAL OF ISLAMIC STUIDES \\ Vol. 1 No. 1(2020): 200-217}

Website: https://journal.stiba.ac.id

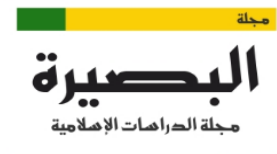

AL-BASHIRAH

\section{JOURNAL OF ISLAMIC STUDIES}

r. الاستغناء في الفرق والاستثناء أو الاعتناء في الفرق والاستثناء(99)، لبدر الدين محمد بن

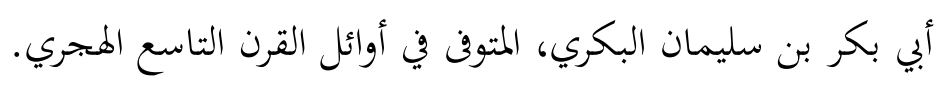

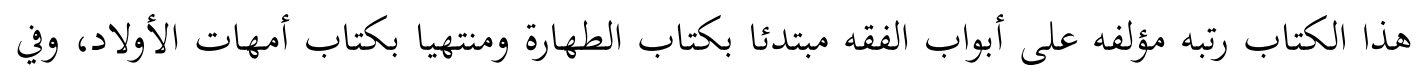

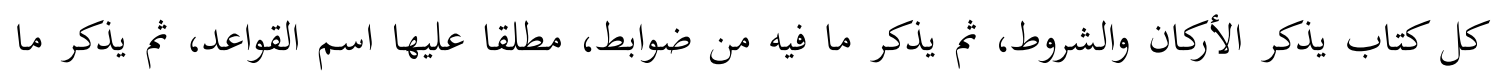

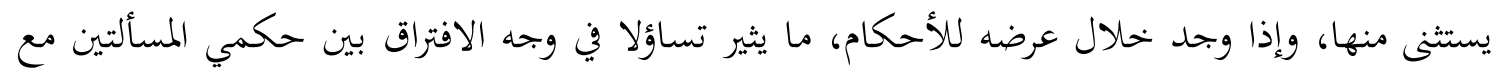

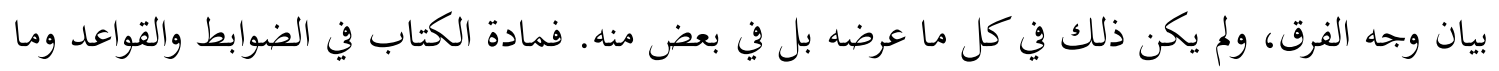

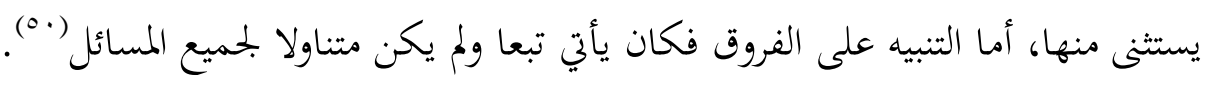

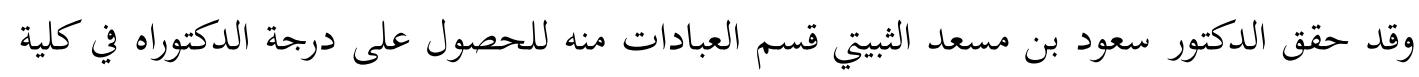

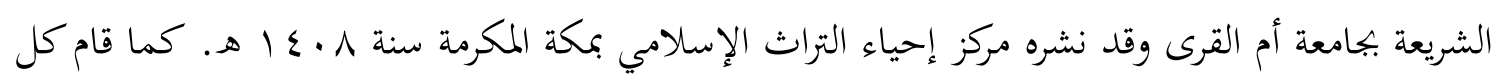

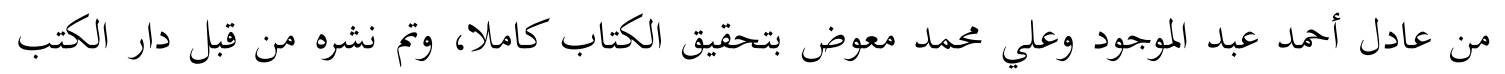

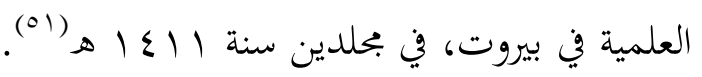
يلاحظ مما تقدم، أن عرض الفروق الفقهية في هذا المسلك لم يكن المن هو الأساس والعمدة، وإنما

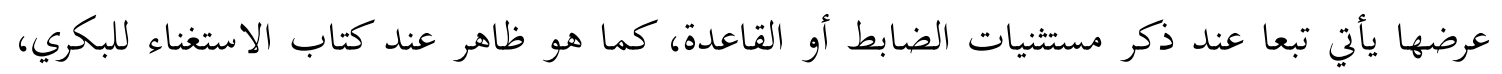

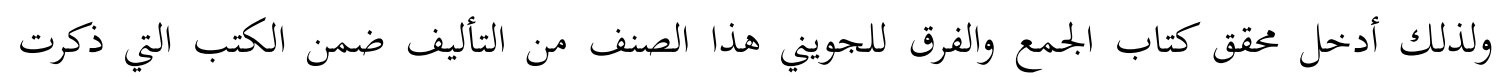
الفروق فيها ضمن فنون أخرى (or).

$$
\text { القسم الثالث: المؤلفات في مسألة واحدة أو مسائل محدودة. }
$$

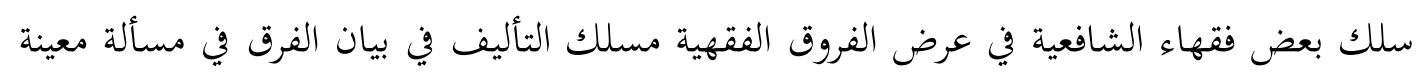

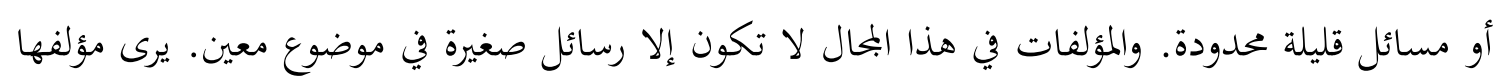

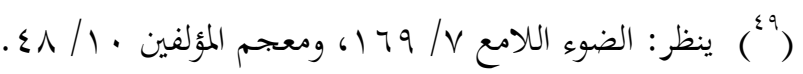

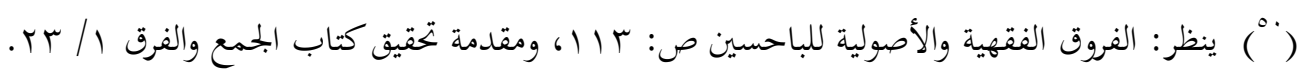

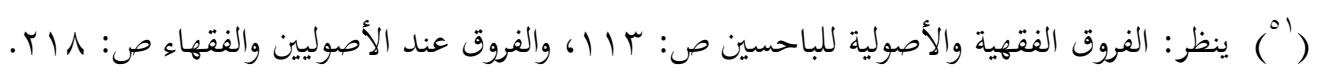
(r)

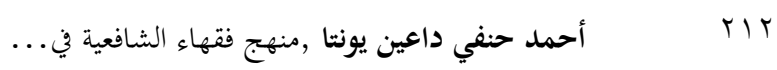




\section{البصيرة: مجلة الدراهات الإهلاهية \\ AL-BASHIRAH: JOURNAL OF ISLAMIC STUIDES \\ Vol. 1 No. 1(2020): 200-217}

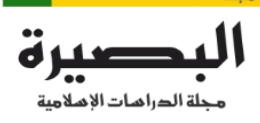

AL-BASHIRAH

Website: https://journal.stiba.ac.id

أنها ربما أوقعت طلبة العلم وغيرهم في الالتباس والخلط بين الأمور المختلفة، على ظن أها شيء واحد.

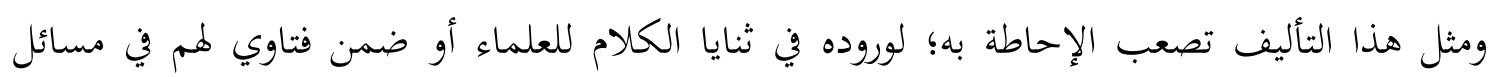
معينة (or) (مثل)

ومن فقهاء الشافعية الذين سلكوا هذا المسلك علي بن عبد الكافي السبكي، المتوفن سنة V07 هـ

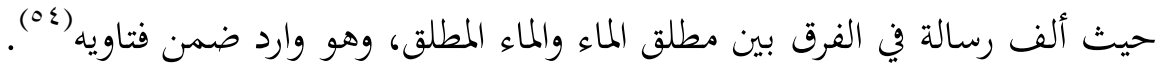

$$
\text { القسم الرابع: المؤلفات التي تناولت الفروق الفقهية تبعا. }
$$

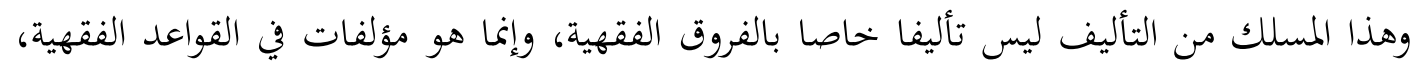
أو الأشباه والنظائر، أي الكتب الجامعة لفنون متعددة، ترتبط فيما بينها برباط معين.

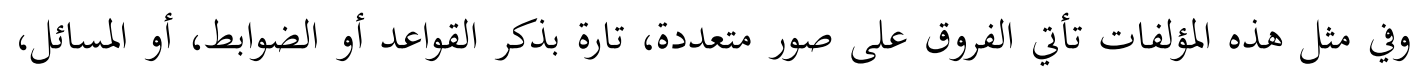

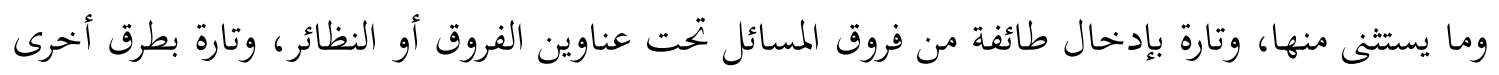
غير ذلك (00).

ومن أبرز ما أُلّف في الأشباه والنظائر في الفقه الشافعي، كتاب الأشباه والنظائر، لجلال الدين عبد

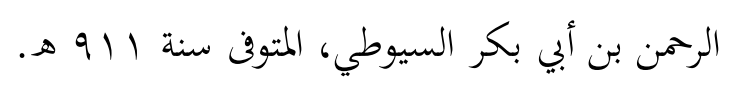

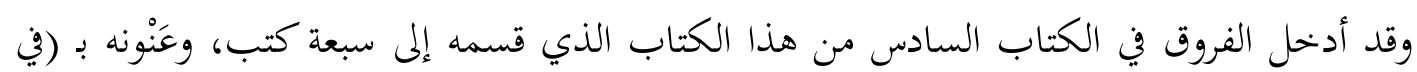

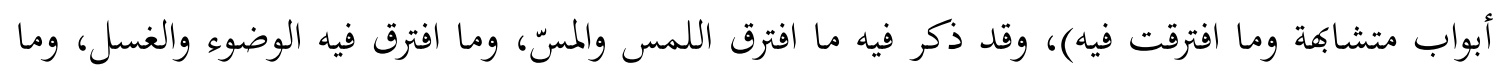

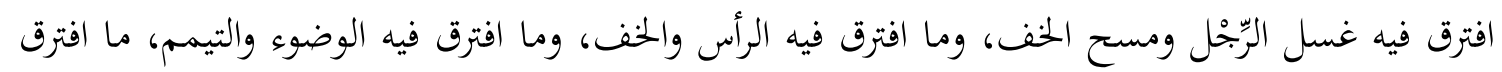

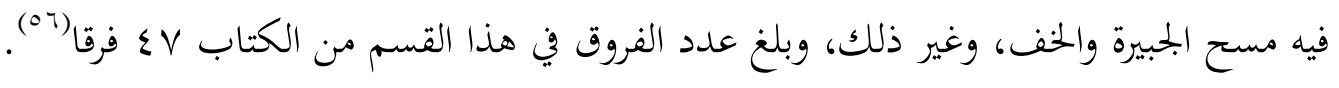

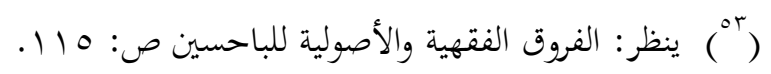

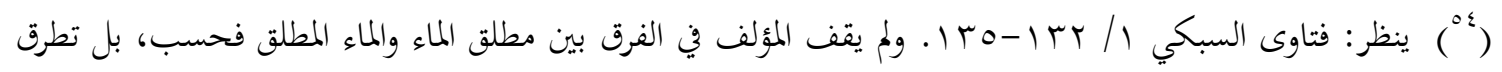

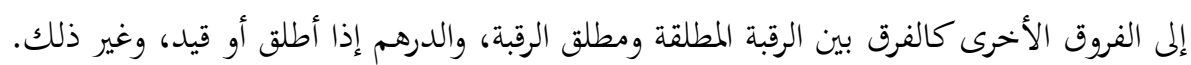

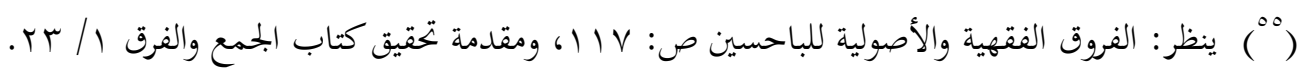

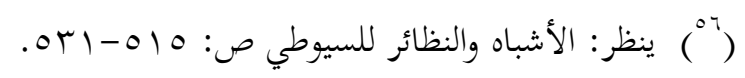

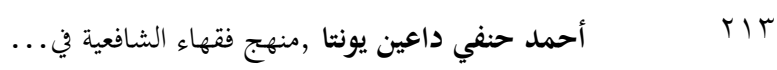




\section{البصيرة: مجلة الدراسات الإسلاهية AL-BASHIRAH: JOURNAL OF ISLAMIC STUIDE்S \\ Vol. 1 No. 1(2020): 200-217

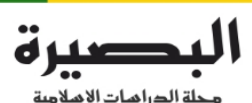 \\ AL-BASHIRAH}

Website: https://journal.stiba.ac.id

وفي الكتاب السابع بعنوان (في نظائر شتى) ذكر فيه بعض الفروق(ナV)، وكذلك في الكتاب

الخامس بعنوان (في نظائر الأبواب) فيها بعض الفروق ذكرها على طريقة ذكر الضوابط وما يستثنى

الخحلاصة والخاتمة:

يمكن استخلاص هذا البحث في النقاط التالية:

1 - مل ميذكر فقهاء الشافعية تعريفا خاصا لهذا العلم، إنما ذكروا وصفا عاما دلا على ماهية هذا

العلم.

r - سلك فقهاء الشافعية في عرض الفروق الفقهية في المؤلفات التي خصصت أو قسم منها بذكر الفروق مسالك عدة، ويمكن حصر هذه المسالك إلى أربعة أقسام:

الأول: المؤلفات في الفروق الفقهية استقلالا.

الثاني: المؤلفات في الفرق والاستثناء.

الثالث: المؤلفات في مسألة واحدة أو مسائل محدودة.

الرابع: المؤلفات التي تناولت الفروق الفقهية تبعا.

هذا، وصلى الله على نبينا محمد وعلى آله وصحبه أجمعين.

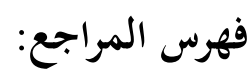

1

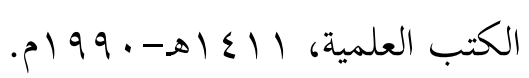

r - الأعلام، خير الدين بن محمود بن محمد بن علي بن فارس، الزركلي الدمشقي، دار العلم

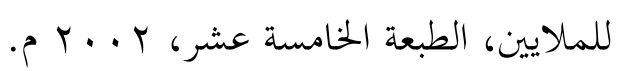

\footnotetext{
( ) ينظر: الأشباه والنظائر للسيوطي ص: البه وما بعدها.

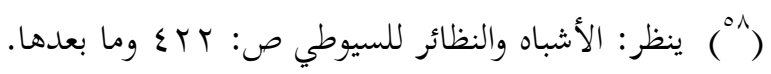

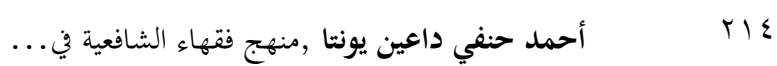




\section{البصيرة: مجلة الدراهات الإهلامية AL-BASHIRAH: JOURNAL OF ISLAMIC STUIDES \\ Vol. 1 No. 1(2020): 200-217}

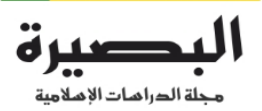

مجلة الصراهات الإصلامية

Website: https://journal.stiba.ac.id

AL-BASHIRAH

r - - أعيان العصر وأعوان النصر، صلاح الدين خليل بن أيبك الصفدي، تحقيق: د/ علي أبو

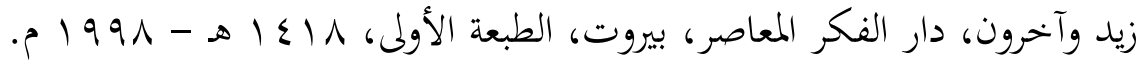

ع -إيضاح الدلائل في الفرق بين المسائل، عبد الرحيم الزريراني، تحقيق: عمر بن محمد السبيل،

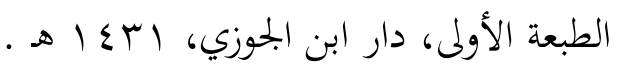

ه - - البحر المحيط في أصول الفقه، أبو عبد الله بدر الدين محمد بن عبد الله بن بهادر الزركشي،

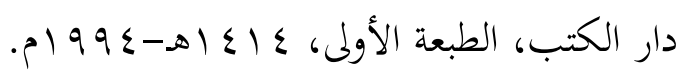

7 - توضيح المشتبه في ضبط أسماء الرواة وأنساهم وألقاهم وكناهم، محمد بن عبد الله بن محمد

بن أحمد بن بحاهد القيسي الدمشقي الشافعي، شمس الدين، الشهير بابن ناصر الدين،

تحقيق: محمد نعيم العرقسوسي، مؤسسة الرسالة، بيروت، الطبعة الأولى، بو9 9 ام.

- V

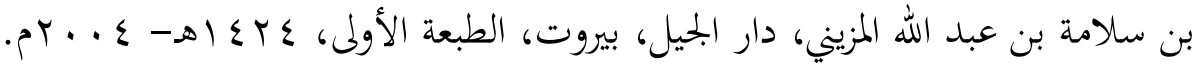

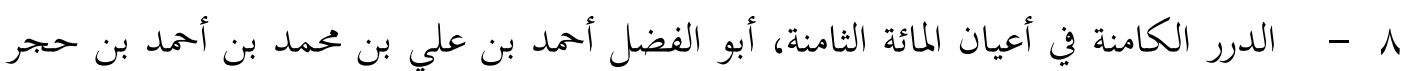

العسقلاني، تحقيق: محمد عبد المعيد ضان، بحلس دائرة المعارف العثمانية، صيدر اباد الهند،

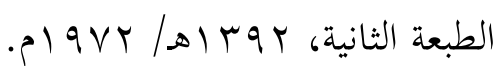

9 - سن أبي داود، أبو داود سليمان بن الأشعث بن إسحاق بن بشير بن شداد بن عمرو

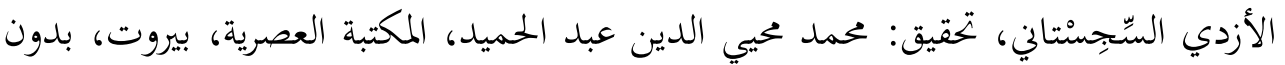

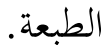

• 1 - السنن الكبرى، أحمد بن الحسين بن علي بن موسى الحُسْرَوْجِردي الخراساني، أبو بكر

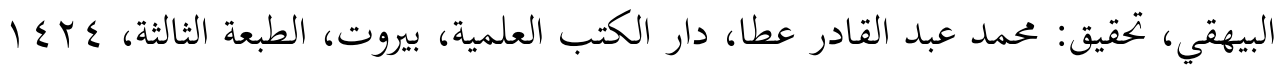

$$
\text { r r. r }
$$

11

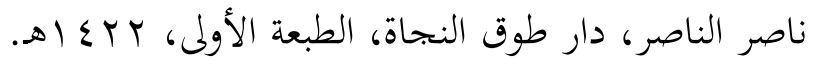

T 1 - صحيح مسلم، مسلم بن الحجاج أبو الحسن القشيري النيسابوري، تحقيق: محمد فؤاد عبد الباقي، دار إحياء التراث العربي، بيروت. 


\section{البصيرة: مجلة الدراهات الإهلامية AL-BASHIRAH: JOURNAL OF ISLAMIC STUIDÉS \\ Vol. 1 No. 1(2020): 200-217}

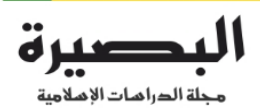

مجلة الدراهات الاهلامية

AL-BASHIRAH

Website: https://journal.stiba.ac.id

با - طبقات الشافعية، أبو بكر بن أحمد بن محمد بن عمر الأسدي الشهبي الدمشقي، تقي

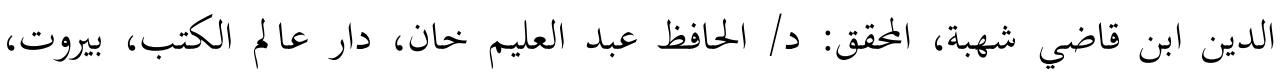

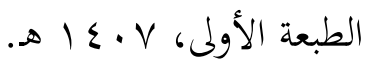

ع ا - طبقات الشافعية، عبد الرحيم بن الحسن بن علي الإسنوي الشافعي، أبو محمد جمال الدين، تحقيق: كمال يوسف الحوت، دار الكتب العلمية، بيروت، الطبعة الأولى، ؟ . . ب م. 10 محمد الطناحي، ود/ عبد الفتاح محمد الحلو، هجر للطباعة والنشر والتوزيع، الطبعة الثانية، $.8 \leqslant$ 17

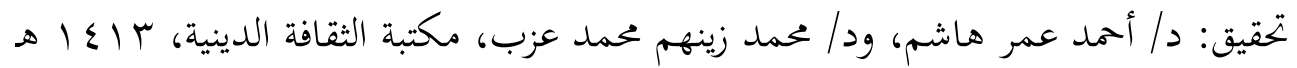
.$<199 \mu-$ - IV الصلاح، تحقيق: محيي الدين علي بنيب، دار البشائر الإسلامية، بيروت، الطبعة الأولى،

$$
.<199 r
$$

11 - العقد المذهب في طبقات حملة المذهب، ابن الملقن سراج الدين أبو حفص عمر بن علي بن أحمد الشافعي المصري، تحقيق: أيمن نصر الأزهري - سيد مهني، دار الكتب العلمية،

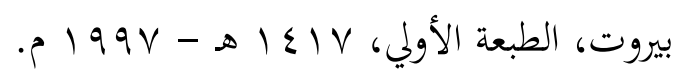

19 - علم الجذل في علم الجدل، سليمان بن عبد القوي بخم الدين الطوفي الحنبلي، تحقيق:

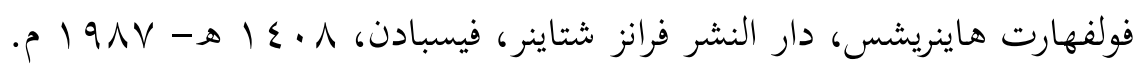

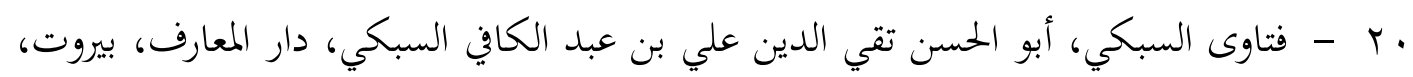

$$
\text { بدون الطبعة. }
$$

ا T - الفروق عند الأصوليين والفقهاء، د/ عبد الرحمن بن عبد الله الشعلان، دار التدمرية، الطبعة

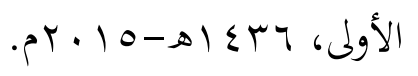

T T - الفروق الفقهية والأصولية، د/ يعقوب الباحسين، مكتبة الرشد الرياض، الطبعة الثالثة، 


\section{البصيرة: مجلة الدراهات الإسلامية AL-BASHIRAH: JOURNAL OF ISLAMIC STUIDES \\ Vol. 1 No. 1(2020): 200-217}

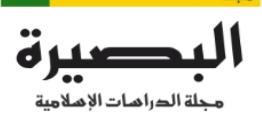

AL-BASHIRAH

Website: https://journal.stiba.ac.id

$$
\cdot p r \cdot|\varepsilon-\infty| \leqslant r_{0}
$$

rr - الفوائد الجنية حاشية المواهب السنية، شرح الفرائد البهية، محمد ياسين بن عيسى الفاداني

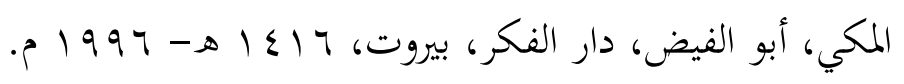

ع T - كشف الظنون عن أسامي الكتب والفنون، مصطفى بن عبد الله كاتب جلبي القسطنطيني

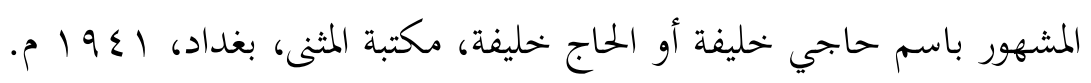

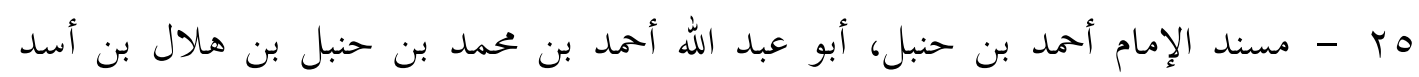

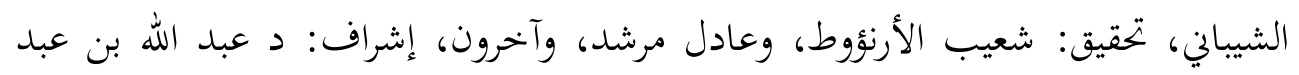

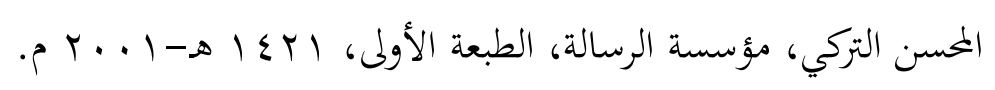

Tب - مطالع الدقائق في تحرير الجوامع والفوارق، عبد الرحيم بن الحسن بن علي الإسنوي

الشافعي، أبو محمد جمال الدين، تحقيق: د/ نصر الدين فريد محمد واصل، دار الشروق،

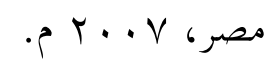

- PV

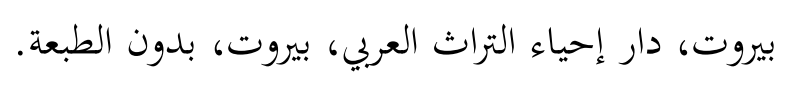

^r - ملحق البدر الطالع بمحاسن من بعد القرن السابع (الملحق التابع للبدر الطالع)، محمد بن

$$
\text { محمد بن يهيى زبارة الحسني اليمني الصنعاني، دار المعرفة، بيروت، بدون الطبعة. }
$$

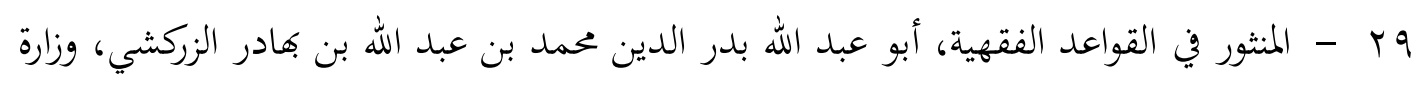

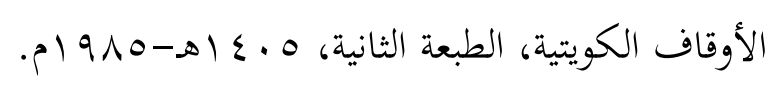

• ץ - هدية العارفين أسماء المؤلفين وآثار المصنفين، إسماعيل باشا البغدادي، مؤسسة التاريخ

$$
\text { العربي، بدون الطبعة. }
$$

